\title{
Spiritual belief and its link with potentially addictive behaviors in a youth sample in Switzerland
}

\author{
${ }^{1}$ Department of Psychiatry, Centre Cantonal Autisme, Lausanne University Hospital, Lausanne, Switzerland. \\ http://orcid.org/0000-0003-2077-3812. \\ 2 Institute of Social Sciences and NCCR LIVES, University of Lausanne, Lausanne, Switzerland \\ ${ }^{3}$ Institute of Social and Preventive Medicine (IUMSP), Lausanne University Hospital, Lausanne 1010, Switzerland \\ 4 Institute of Social and Preventive Medicine (IUMSP), Lausanne University Hospital, Route de la Corniche 10, Lausanne 1010, \\ Switzerland, Phone: +41 213147375 , Fax: +41 213147373 , E-mail: joan-carles.suris@chuv.ch
}

\begin{abstract}
:
Background: Earlier studies suggested a positive impact of spirituality on addictive disorders, but this effect has rarely been studied in a large adolescent and young adult population.

Aim: To examine the association between spiritual beliefs (general belief, the supporting role of spiritual belief, the critical role of spiritual belief) and potentially addictive behaviors (tobacco, alcohol, cannabis and other illegal drugs, excessive Internet use and gambling).

Methods: Data were collected using online self-report questionnaires among a sample of 5179 adolescents and young adults aged 15-24 years in post-mandatory education in Switzerland. Statistical analysis at bivariate and multivariate level was performed.

Results: At the bivariate level, spiritual beliefs were linked to a lower risk of tobacco smoking, alcohol misuse and cannabis use as well as an increased risk of Internet overuse and gambling. However, at the multivariate level, controlling for age, gender, language and place of birth, significant associations were found only for alcohol misuse, Internet overuse and gambling.

Conclusion: The study provides evidence that spiritual belief could protect youth from the risk of alcohol misuse but could also increase the risk of excessive Internet use and gambling. The role of spiritual beliefs in preventing or motivating these problematic behaviors is of great interest for adolescent health care providers and should be considered in the light of the separation-individuation process and transition from adolescence to adulthood.
\end{abstract}

Keywords: addictive behaviors, spiritual belief, youth

DOI: $10.1515 /$ ijamh-2018-0070

Received: April 6, 2018; Accepted: June 5, 2018

\section{Introduction}

The term "spirituality" which has its origin in religion, has developed and expanded over time and is actually considered as a cultural fact. It refers to certain kinds of activity through which a person "searches for the sacred" [1] and seeks answers and meaning in one's life. According to Janse van Rensburgh et al. [2], spirituality includes (but is not limited to) religion and relations with others. Murray and Zentner [3] (p. 116) define spirituality in this way: "In every human being there seems to be a spiritual dimension, a quality that goes beyond religious affiliation and strives for inspiration, reverence, awe, meaning and purpose, even in those who do not believe in God. The spiritual dimension tries to be in harmony with the universe and strives for answers about the infinite". Its link with one's personal identity and relations with others has been supposed to play an important role in coping mechanisms which impact on the physical and mental states of everyone. The literature is, for example, in accordance with a protecting effect of religiousness/spirituality in patients with addictive and dependent behaviors [4] as well as in patients with suicidal ideation and attempts [5]. These authors suggest that religiousness/spirituality might impact positively on the evolution of these disorders in a supportive manner or acting as an external control of impulsive behaviors. 
Adolescence is known to be a critical period for the developmental balance between excitatory and inhibitory synaptic strength, and a critical tuning phase towards brain maturation associated with an increased vulnerability for prodrome and emergence of psychopathology [6]. Many youth develop their addictive behaviors during adolescence [7]. Such an increased risk for addictive behaviors in adolescents has been explained by neuro-cognitivists using a dual-process model: "implicit or automatically activated (impulsive) processes gain in relative control over substance use (addictive) behavior when the moderating influence of reflective processes on the addictive behavior weakens" [8] (p. 141). There is a normative developmental discrepancy (maturational imbalance) between the impulsive, motivational processes (increased reward reactivity and risk taking) and the reflective, cognitive control processes in adolescents [8], [9]. Addictive behaviors could further lead to additional functional and structural alternations in brain functioning related to inhibitory control, as the adolescent brain is shown to be especially sensitive to the harmful effects of substance use [10]. Factors that can have an impact on this developmental imbalance may be of great interest for the prevention and treatment of addictive disorders among youth.

From a sociological point of view, adolescence represents a particularly stressful period of individualization, independence, transition to adulthood and forthcoming home-leaving. In this context, multiple protective and risk factors could influence the young person's behavior. Protective factors promote pro-social behaviors while risk factors increase the likelihood of risk behaviors [11], [12]. Young people with high levels of protective factors will be less likely to engage in risk behaviors. For example, high religiosity is considered to have a regulatory control function and be a protective factor [12].

The association between spiritual beliefs and addictive behaviors has rarely been studied in a large adolescent and young adult population (AYAs). The present study aimed to investigate the link between spirituality and addictive behaviors among a sample of youths in Switzerland. As target addictive behaviors, we included the most frequently studied ones (tobacco, alcohol, cannabis and other illegal drugs, Internet addiction, pathological gambling) according to recent population-based studies in Swiss youths [13], [14], [15].

We hypothesized that spiritual beliefs could modify addictive behaviors in AYAs as has been reported in adults. More precisely, we supposed that spiritual beliefs could protect AYAs from potentially addictive behaviors. Furthermore, we investigated explicitly both the supporting role and the external inhibitory control role (formulated in the current study as critical role) of spiritual beliefs suggested by already mentioned earlier studies and hypothesized that these two components could protect AYAs from potentially addictive behaviors to the same extent.

\section{Methods}

\section{Participants}

Data were drawn from the first wave of GenerationFRee, a study including a post-mandatory education (high schools or professional schools) sample of 5179 youths living in the canton of Fribourg of Switzerland where two thirds of the population speak French and one third speak German. Data were collected during the 20142015 school year using an anonymous online self-administrated questionnaire and were weighted to accurately represent the structure of the population under study. The Ethics Committee of the Canton of Vaud approved the study.

\section{Variables}

Spiritual beliefs were measured by asking to what extent participants believed in a spiritual higher power (general spiritual belief), in its supporting role ("support and help you") and in its critical role ("keep watch on you and could punish"). For each of these three variables, participants were divided into two subgroups: "group without certainty about their belief" (who indicated that they do not believe or still have doubts) and "group with certainty about their belief" (who reported that they believe or strongly believe).

Socio-demographic variables included gender, age, language (French or German) and birthplace (Switzerland or other countries). In order to assess the age effect, participants were divided into younger AYAs subgroup (15-19 years old) and older AYAs subgroup (20-24 years old).

Potentially addictive behaviors were measured by asking about their current tobacco smoking (smoking or not), cannabis use (at least once during the past month), use of illegal substances other than cannabis (at least once during the past month) and alcohol misuse (at least one episode of drunkenness during the past month). 
The short version of the Internet Addiction Test (s-IAT) was used to evaluate the level of excessive Internet use [16]. The s-IAT includes 12 items and each one is rated on a five-point scale ranging from 1 (never) to 5 (very often). Scores are added with a result above 29 over 60 suggesting excessive Internet use.

Gambling behavior was evaluated with the South Oaks Gambling Screen Revised for Adolescents (SOGSRA) [17], a 12-item instrument that explores general behavior related to gambling on a scale from 0 to 12 points. The three possible outcomes and scores - ("no problem gambler" ( $<2$ points), "at risk gambler" ( $\geq 2-<4$ points) and "problematic gambler" ( $\geq 4$ points) - were dichotomized into "no problem gambler" $(<2$ points and including non-gamblers) and "at risk gambler" ( $\geq 2$ points).

\section{Statistical analysis}

Statistical analysis was performed with Stata 14 (StataCorp, College Station, TX, USA). Statistical significance was set to $p<0.05$. We firstly ran general descriptive statistics on the AYAs' beliefs, on the prevalence of potentially addictive behaviors as well as their gender-, age-, language- and birthplace-difference. Secondly, for each question about spiritual belief, we assessed the characteristics of subgroups of belief by comparing them with associated potential addictive behaviors (substance use, Internet overuse, risk gambling). We used chisquare $\left(\chi^{2}\right)$-tests for categorical variables and t-tests for continuous variables. Statistically significant variables were then entered in a logistic regression, controlling for age, gender, language and birthplace, to predict how AYAs' certainty about spiritual beliefs could be linked with potentially addictive behaviors.

\section{Results}

\section{Descriptive statistics}

Table 1 summarizes socio-demographic data. Participants were aged 15-24 years with a mean age of 18.31 (Standard error $=0.04$ ) and no gender difference. Overall, $42.7 \%$ of the participants reported certainty about their belief in a spiritual higher power, $35.0 \%$ about the supporting role of their belief and $24.1 \%$ about the critical role of their belief (Table 1). Females, German-speaking and non-Swiss born participants were significantly more likely to have certainty about their spiritual belief.

Male participants were significantly more likely to report all potential addictive behaviors. Older participants were significantly more likely to be current smokers, to use cannabis and other illegal drugs and to be at-risk gamblers. German-speaking participants were significantly less likely to report Internet addiction. NonSwiss born participants were significantly less likely to misuse alcohol but more likely to use other illegal drugs and to report excessive Internet use and risk gambling behaviors.

\section{Bivariate analysis}

At the bivariate level (Table 2), participants with certainty about their general spiritual belief, were significantly less likely to be current smokers, to misuse alcohol and to use cannabis and more likely to be at-risk gamblers than participants without certainty. 


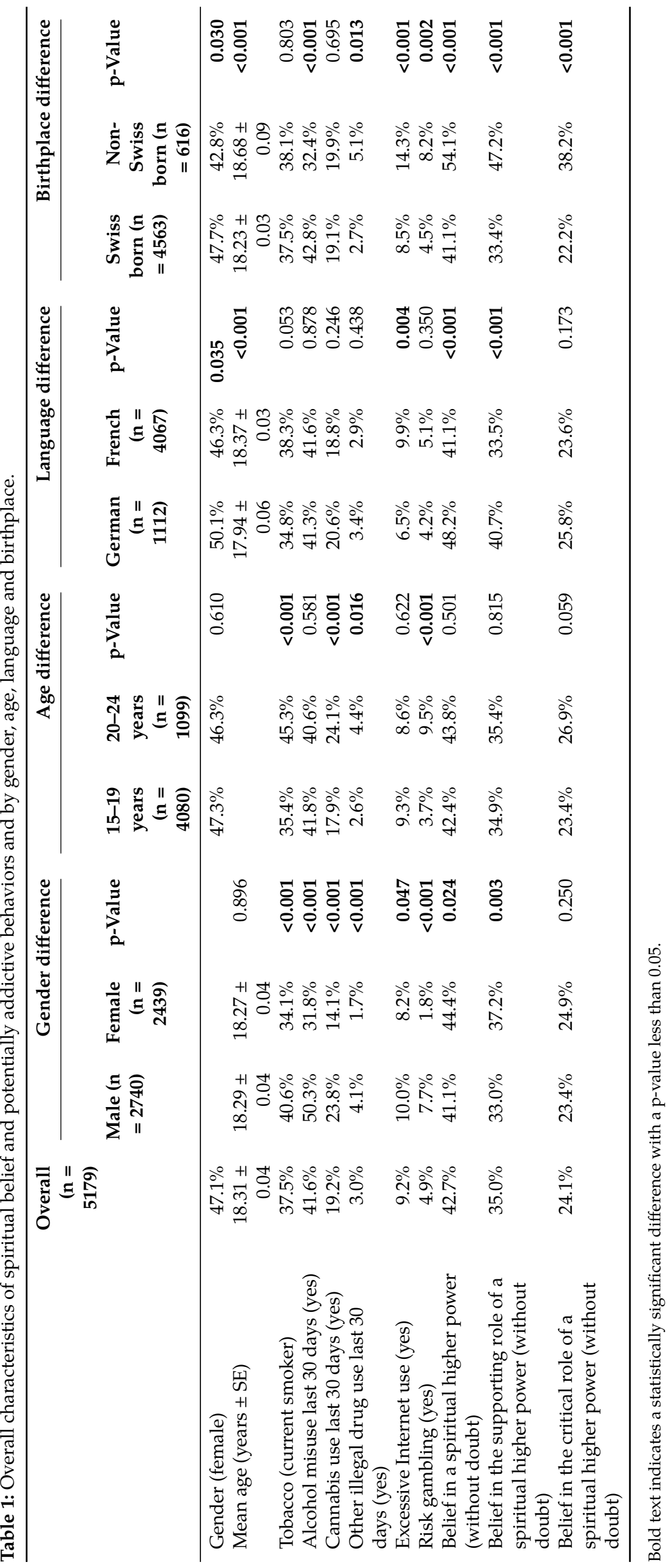


Table 2: Bivariate analysis comparing the two groups ${ }^{a}$ of spiritual belief.

\begin{tabular}{|c|c|c|c|c|c|c|c|c|c|}
\hline & \multicolumn{3}{|c|}{$\begin{array}{r}\text { Belief in a spiritual higher } \\
\text { power }\end{array}$} & \multicolumn{3}{|c|}{ Belief in its supporting role } & \multicolumn{3}{|c|}{ Belief in its critical role } \\
\hline & $\begin{array}{r}\text { Group } \\
1(n= \\
2970)\end{array}$ & $\begin{array}{c}\text { Group } \\
2(n= \\
2209)\end{array}$ & p-Value & $\begin{array}{r}\text { Group } \\
1(\mathrm{n}= \\
3365)\end{array}$ & $\begin{array}{r}\text { Group } \\
2(\mathrm{n}= \\
1814)\end{array}$ & p-Value & $\begin{array}{r}\text { Group } \\
1(n= \\
3931)\end{array}$ & $\begin{array}{r}\text { Group } \\
2(\mathrm{n}= \\
1248)\end{array}$ & p-Value \\
\hline $\begin{array}{l}\text { Tobacco (current } \\
\text { smoker) }\end{array}$ & $38.9 \%$ & $35.7 \%$ & 0.031 & $39.0 \%$ & $34.9 \%$ & 0.008 & $37.5 \%$ & $37.7 \%$ & 0.903 \\
\hline $\begin{array}{l}\text { Alcohol misuse } \\
\text { last } 30 \text { days (yes) }\end{array}$ & $45.6 \%$ & $36.1 \%$ & $<0.001$ & $45.4 \%$ & $34.4 \%$ & $<0.001$ & $43.4 \%$ & $35.6 \%$ & $<0.001$ \\
\hline $\begin{array}{l}\text { Cannabis use last } \\
30 \text { days (yes) }\end{array}$ & $20.6 \%$ & $17.3 \%$ & 0.010 & $20.6 \%$ & $16.6 \%$ & 0.002 & $19.7 \%$ & $17.7 \%$ & 0.174 \\
\hline $\begin{array}{l}\text { Other illegal drug } \\
\text { use last } 30 \text { days } \\
\text { (yes) }\end{array}$ & $2.7 \%$ & $3.3 \%$ & 0.293 & $2.8 \%$ & $3.3 \%$ & 0.438 & $2.6 \%$ & $4.0 \%$ & 0.039 \\
\hline $\begin{array}{l}\text { Excessive Internet } \\
\text { use (yes) }\end{array}$ & $8.8 \%$ & $9.7 \%$ & 0.296 & $8.5 \%$ & $10.4 \%$ & 0.047 & $7.8 \%$ & $13.5 \%$ & $<0.001$ \\
\hline $\begin{array}{l}\text { Risk gambling } \\
\text { (yes) }\end{array}$ & $3.9 \%$ & $6.3 \%$ & 0.002 & $4.2 \%$ & $6.3 \%$ & 0.005 & $4.1 \%$ & $7.5 \%$ & 0.001 \\
\hline
\end{tabular}

${ }^{a}$ Group 1 = Belief without certainty; Group 2 = Belief with certainty. Bold text indicates a statistically significant difference with a p-value less than 0.05 .

Participants with certainty about the supporting role of their spiritual belief were significantly less likely to be current smokers, to misuse alcohol and to use cannabis while they showed a significantly greater risk for excessive Internet use and risk gambling behaviors.

Finally, participants with certainty about the critical role of their spiritual belief were significantly less likely to misuse alcohol while they showed a significantly greater risk for the use of other illegal drugs, excessive Internet use and gambling.

\section{Logistic regression analysis}

W When controlling for gender, age, language and birthplace (Table 3), our logistic regression models revealed three potentially addictive behaviors whose risk seemed to be significantly linked with the certainty about AYAs' spiritual belief.

Table 3: Logistic regression analysis between spiritual belief and potentially addictive behaviors. ${ }^{\mathrm{a}}$

\begin{tabular}{|c|c|c|c|c|c|c|c|c|c|}
\hline & \multicolumn{3}{|c|}{$\begin{array}{r}\text { Belief in a spiritual higher } \\
\text { power }\end{array}$} & \multicolumn{3}{|c|}{ Belief in its supporting role } & \multicolumn{3}{|c|}{ Belief in its critical role } \\
\hline & $\overline{\text { OR }}$ & p-Value & $\begin{array}{r}95 \% \text { conf. } \\
\text { interval }\end{array}$ & OR & p-Value & $\begin{array}{r}95 \% \text { conf. } \\
\text { interval }\end{array}$ & OR & p-Value & $\begin{array}{r}95 \% \text { conf. } \\
\text { interval }\end{array}$ \\
\hline $\begin{array}{l}\text { Tobacco (current } \\
\text { smoker) }\end{array}$ & 0.98 & 0.725 & $0.85-1.12$ & 0.96 & 0.540 & $0.83-1.10$ & & & \\
\hline $\begin{array}{l}\text { Alcohol misuse last } \\
30 \text { days (yes) }\end{array}$ & 0.70 & $<0.001$ & $0.61-0.80$ & 0.67 & $<0.001$ & $0.58-0.77$ & 0.71 & $<0.001$ & $0.61-0.83$ \\
\hline $\begin{array}{l}\text { Cannabis use last } \\
30 \text { days (yes) }\end{array}$ & 0.90 & 0.219 & $0.75-1.07$ & 0.87 & 0.145 & $0.72-1.05$ & & & \\
\hline $\begin{array}{l}\text { Other illegal drug } \\
\text { use last } 30 \text { days } \\
\text { (yes) }\end{array}$ & & & & & & & 1.37 & 0.131 & $0.91-2.05$ \\
\hline $\begin{array}{l}\text { Excessive Internet } \\
\text { use (yes) }\end{array}$ & & & & 1.23 & 0.067 & $0.99-1.55$ & 1.74 & $<0.001$ & $1.38-2.20$ \\
\hline Risk gambling (yes) & 1.85 & $<0.001$ & $1.35-2.52$ & 1.78 & $<0.001$ & $1.30-2.45$ & 1.80 & 0.001 & $1.29-2.51$ \\
\hline
\end{tabular}

${ }^{a}$ Controlled for age, gender, language and birthplace. Bold text indicates a statistically significant difference with a p-value less than 0.05 . OR: odds ratio. CI: confidence interval. 
The risk of alcohol misuse was significantly reduced by the certainty about their general spiritual belief [OR: 0.70, 95\% CI: 0.61-0.80], by the certainty about the supporting role of belief (OR: $0.67,95 \%$ CI: $0.58-0.77$ ) and by the certainty about the critical role of belief (OR: 0.71, 95\% CI: 0.61-0.83).

The risk of Internet addiction was significantly increased by the certainty about the critical role of belief (OR: 1.74, 95\% CI: 1.38-2.20).

Risk gambling behaviors were significantly increased by the certainty about their general spiritual belief (OR: 1.85, 95\% CI: 1.35-2.52), by the certainty about the supporting role of belief (OR: 1.78, 95\% CI: 1.30-2.45) and by the certainty about the critical role of belief (OR: 1.80, 95\% CI: 1.29-2.51).

\section{Discussion}

The present study aimed to investigate the spiritual belief and its link with potentially addictive behaviors in a sample of AYAs in Switzerland. More than $40 \%$ of them claimed their certainty to believe in a spiritual higher power. This relatively high rate of spiritual belief is not surprising as Fribourg is known to be a traditional catholic canton with higher than national average level of religiosity [18]. This rate is also similar to what has been described in earlier studies [19].

As presumed, we found a significant association between spiritual beliefs and some potentially addictive behaviors when age, gender, language and birthplace were controlled for. AYAs' certainty about their spiritual belief seemed to significantly protect them from the risk of alcohol misuse. A widely accepted explanation in the literature is that religiosity/spirituality could potentially affect alcohol use through its values promoting pro-social supporting networks and against alcohol-abuse [20]. In the present study, the observed "double protective effects" of spiritual belief via its "supporting role" and "critical role" against alcohol misuse is in accordance with this explanation. However, a similar significant protective role was not found for other substances (tobacco smoking, cannabis use, other illegal drugs) at the multivariate level. This is partly in accordance with earlier findings suggesting sparse evidence about such an effect on substances other than alcohol and cannabis. On the contrary, a large body of data is available in the literature supporting the protective role of religiosity/spirituality against alcohol and cannabis use [21], [22], [23]. The present study did not succeed in replicating such result for cannabis use. One possibility is that spirituality might be an approach more individually oriented than religiosity and each type of substance-abusing behavior might be associated with unique motivations and thus linked to different dimensions of spirituality [24]. For example, Giordano et al. [24] investigated the relationship between cannabis use and four dimensions of spirituality (purpose/meaning, innerness, unifying interconnectedness, transcendence) in university students aged 18-25 years and found significant results only in two dimensions: purpose/meaning (engagement in activities or relationships that support self-worth, instill and provide meaning to life), and innerness (knowledge and use of self-strengths, internal peace and reliance on self for decision making). As the authors proposed, "empirical studies designed to understand the unique relationships between religion/spirituality and specific types of substance-abusing behaviors" are still needed. Another possible explanation is that the presumed protective role of spirituality on cannabis use might be not simply due to the spiritual belief per se but to an indirect role of spiritual belief via "risk perception" [25] especially when many Swiss youths seem tolerant towards cannabis use and consider it as less harmful than tobacco, alcohol and other hard drugs [26].

Contrary to our initial hypothesis, our results showed an increased risk of excessive Internet use and gambling in AYAs with certainty about their spiritual beliefs. One possible explanation is that spiritual beliefs could reinforce some functions of these two potentially addictive behaviors in AYAs' lives. Curiously, a previous Australian survey in adults reported higher rates of problem gambling linked to religiosity/spirituality, and self-reports of these participants revealed that gambling could be perceived as giving hope and opportunity for a better life [27]. A more recent study in a Chinese sample of 801 adults evaluated the link between problem gambling and positive psychological dispositions such as gratitude, hope and personal growth initiative and reported a protective role of gratitude and hope on problem gamblings [28]. Meanwhile, a higher rate of personal growth initiative (conceived as "a person's active and intentional contribution in evolving and developing") predicted more severe problem gambling [28]. Considering adolescence as a particularly stressful period of individualization, independence, transition to adulthood and forthcoming home leaving, the search for relationship changes and financial independence could be associated with a higher rate of personal growth initiative and motivate gambling behaviors. A person with certainty about spiritual beliefs could think that the spiritual higher power in which he trusts can "help him win" [27]. Spiritual belief could increase the risk of Internet addiction in the same way as online gambling is becoming more and more frequent in adolescents with increased Internet accessibility and online adolescent gamblers showed similar characteristics to landbased adolescent gamblers [29]. Problematic adolescent gamblers are also more likely to be problematic Inter- 
net users [30]. Future studies using qualitative methods are needed to explore more closely these associations and gain further knowledge in how spiritual beliefs contribute to the increased risk for excessive Internet use and gambling.

It is interesting that the risk of excessive Internet use was particularly increased by AYAs' certainty about the critical role of spiritual belief. In the context of transition from adolescence to adulthood, "the spiritual development provides a person with insight and understanding of self and other" [31]. The critical role of spiritual belief plays a role of "external inhibitory control" on spiritual disapproving behaviors, just like the internalized rules of super-ego mainly taught by parents during childhood according to the traditional psychodynamic theories. During the separation-individuation process, adolescent "rule-transgressing" behaviors are common. Internet use plays an important role during this period, promoting not only adolescent's identity formation (Internet as a tool to develop interests and expertise, to seek and maintain friendships) but also autonomy by providing a private space, and a way for adolescents to negotiate and test parental rules [32]. A recent study among 2021 Chinese adolescents revealed that parental restricted Internet use was associated with a higher rate of Internet addiction [33]. Alternatively, another study [34] reported a positive association between religious belief (moral disapproval) and perceived addiction to Internet pornography in young adults, suggesting a religiosity-mediating perception of potentially addictive behaviors considered by themselves as transgressive to the religious values. Our results further suggest that the relationship between the perceived critical role of spiritual belief and AYAs' excessive Internet use might not be simply causal but interactive and modified (and motivated) by a normal development of adolescent separation-individuation process.

The present study also reported a sex difference in AYAs' addictive behaviors. Being female was associated with a lower risk of all the studied addictive behaviors. This is in accordance with the literature [35].

The main strength of the current study is that it is based on a large sample size. Given that the link between spiritual beliefs and their potentially addictive behaviors has rarely been studied in a large AYAs population, our results could help improve the understanding, preventing and treating addictive behaviors during adolescence.

Some limitations need to be mentioned. The cross-sectional nature of the study does not allow to draw conclusions about causal relationships. The nature and the conception of one's spiritual belief during adolescence in our case are self-reported and it might be interesting to investigate it more in detail.

\section{Acknowledgments}

The GenerationFree study is financed by Le Programme Intercantonal de Lutte contre la Dépendance au Jeu (PILDJ) and the canton of Fribourg (Switzerland).

Conflict of interest: The authors declare that they have no conflict of interest.

\section{References}

[1] Pargament KI. The psychology of religion and coping: theory, research, practice. New York, NY: Guilford Publications; 1997.

[2] Janse van Rensburg AB, Myburgh CP, Szabo CP, Poggenpoel M. The role of spirituality in specialist psychiatry: a review of the medical literature. Afr] Psychiatry (Johannesbg). 2013;16(4):247-55.

[3] Murray RB, Zentner ]P. Health promotion strategies through the life span, 7th ed. Saddle River, N]: Prentice Hall; 2001.

[4] De Fazio P, Gaetano R, Caroleo M, Cerminara G, Giannini F, Jaén Moreno M], et al. Religiousness and spirituality in patients with bipolar disorder. Int ] Psychiatry Clin Pract. 2015;19(4):233-7.

[5] Burshtein S, Dohrenwend BP, Levav I, Werbeloff N, Davidson M, Weiser M. Religiosity as a protective factor against suicidal behaviour. Acta Psychiatr Scand. 2016;133(6):481-8.

[6] Insel TR. Rethinking schizophrenia. Nature. 2010;468(7321):187-93.

[7] Eaton DK, Kann L, Kinchen S, Shanklin S, Ross ], Hawkins ], et al. Youth risk behavior surveillance - United States, 2007. MMMWR Morb Mortal Wkly Report. 2008;57(SSO4): 1-131. Available from: https://www.cdc.gov/mmwr/preview/mmwrhtml/ss5704a1.htm.

[8] Wiers RW, Boelema SR, Nikolaou K, Gladwin TE. On the development of implicit and control processes in relation to substance use in adolescence. Curr Addict Rep. 2015;2(2):141-55.

[9] Hammond C], Mayes LC, Potenza MN. Neurobiology of adolescent substance use and addictive behaviors: treatment implications. Adolesc Med State Art Rev. 2014;25(1):15-32.

[10] López-Caneda E, Rodríguez Holguín S, Cadaveira F, Corral M, Doallo S. Impact of alcohol use on inhibitory control (and vice versa) during adolescence and young adulthood: a review. Alcohol Alcohol. 2014;49(2):173-81.

[11] Jessor R, Turbin MS, Costa FM, Dong Q, Zhang H, Wang C. Adolescent problem behavior in China and the United States: a cross-national study of psychosocial protective factors. ] Res Adolesc. 2003;13(3):329-60. 
[12] Egondi T, Kabiru C, Beguy D, Kanyiva M, Jessor R. Adolescent home-leaving and the transition to adulthood: a psychosocial and behavioural study in the slums of Nairobi. Int ] Behav Dev. 2013;37(4):298-308.

[13] Rücker ], Akre C, Berchtold A, Suris ]-C. Problematic Internet use is associated with substance use in young adolescents. Acta Paediatr. 2015;104(5):504-7.

[14] Suris ]-C, Akre C, Piguet C, Ambresin A-E, Zimmermann C, Berchtold A. Is Internet use unhealthy? A cross-sectional study of adolescent Internet overuse. Swiss Med Wkly. 2014;144:W14061.

[15] Tozzi L, Akre C, Fleury-Schubert A, Suris ]-C. Gambling among youths in Switzerland and its association with other addictive behaviours. A population-based study. Swiss Med Wkly. 2013;143:W13768.

[16] Pawlikowski M, Altstötter-Gleich C, Brand M. Validation and psychometric properties of a short version of Young's Internet Addiction Test. Comput Hum Behav. 2013;29(3):1212-1223.

[17] Boudreau B, Poulin C. The South Oaks Cambling Screen-revised Adolescent (SOCS-RA) revisited: a cut-point analysis. J Gambl Stud. 2007:23(3):299-308.

[18] Canton of Fribourg. 2017 statistic reports of the canton of Fribourg. [Internet]. Available from: http://www.fr.ch/sstat/files/pdf9o/annuaire_internet_2017.pdf.

[19] Roehlkepartain EC, King PE, Wagener LM, Benson PL. The handbook of spiritual development in childhood and adolescence, 1st ed. Thousand Oaks, CA: Sage Publications, Inc; 2005.

[20] Porche MV, Fortuna LR, Wachholtz A, Stone RT. Distal and proximal religiosity as protective factors for adolescent and emerging adult alcohol use. Religions (Basel). 2015;6(2):365-84.

[21] Stewart C. The influence of spirituality on substance use of college students. ] Drug Educ. 2001;31(4):343-51.

[22] Chitwood DD, Weiss ML, Leukefeld CG. A systematic review of recent literature on religiosity and substance use.] Drug Issues. 2008;38(3):653-88.

[23] Dennis DL, Cox W, Black A, Muller S. The influence of religiosity and spirituality on drinking behaviors: differences between students attending two southern universities. J Drug Educ. 2009;39(1):95-112.

[24] Ciordano AL, Prosek EA, Daly CM, Holm JM, Ramsey ZB, Abernathy MR, et al. Exploring the relationship between religious coping and spirituality among three types of collegiate substance abuse. J Couns Dev. 2015;93(1):70-9.

[25] Hai AH. Cender differences in the relationships among young adults' religiosity, risk perception, and marijuana use: a moderated mediation model. Subst Use Misuse. 2017;0(0):1-10.

[26] Menghrajani P, Klaue K, Dubois-Arber F, Michaud P-A. Swiss adolescents' and adults' perceptions of cannabis use: a qualitative study. Health Educ Res. 2005;20(4):476-84.

[27] Clarke D, Abbott M, Tse S, Townsend S, Kingi P, Manaia W. Cender, age, ethnic and occupational associations with pathological gambling in a New Zealand urban sample. NZ] Psychol. 2006;35(2):84-91.

[28] Loo ]M, Tsai J-S, Raylu N, Oei TP. Gratitude, hope, mindfulness and personal-growth initiative: buffers or risk factors for problem gambling? PLoS One. 2014;9(2):e83889.

[29] Wijesingha R, Leatherdale ST, Turner NE, Elton-Marshall T. Factors associated with adolescent online and land-based gambling in Canada. Addict Res Theory. 2017;25(6):525-32.

[30] Suris ]C, Akre C, Petzold A, Herzig D, Michaud P-A. 53. Is gambling part of a global addiction behavior?] Adolesc Health. 2012;50(2):S40.

[31] Oluwole DA. Spirituality, gender and age factors in cyber gossip among Nigerian adolescents. Cyberpsychol Behav. 2009;12(3):323-6.

[32] Borca G, Bina M, Keller PS, Gilbert LR, Begotti T. Internet use and developmental tasks: adolescents' point of view. Comput Human Behav. 2015;52(Supplement C):49-58.

[33] Wu CST, Wong HT, Yu KF, Fok KW, Yeung SM, Lam CH, et al. Parenting approaches, family functionality, and internet addiction among Hong Kong adolescents. BMC Pediatrics. 2016;16:130.

[34] Crubbs ]B, Exline ]J, Pargament KI, Hook JN, Carlisle RD. Transgression as addiction: religiosity and moral disapproval as predictors of perceived addiction to pornography. Arch Sex Behav. 2015;44(1):125-36.

[35] Kuhn C. Emergence of sex differences in the development of substance use and abuse during adolescence. Pharmacol Ther. 2015;153:5578. 